\title{
Tautomerism and Self-Association in the Solution of New Pinene-Bipyridine and Pinene-Phenanthroline Derivatives
}

\author{
Atena B. Solea ${ }^{1,2}{ }^{\oplus}$, Ivan Cornu ${ }^{1}$, Vera Deneva $\left.{ }^{3}{ }^{(}\right)$, Aurelien Crochet ${ }^{1}{ }^{1}$, Katharina M. Fromm ${ }^{2}$,

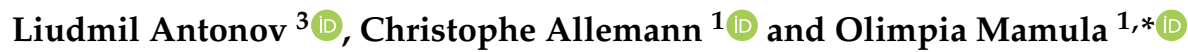 \\ 1 Haute Ecole d'Ingénierie et d'Architecture Fribourg, HES-SO University of Applied Sciences of Western \\ Switzerland, Pérolles 80, CH-1705 Fribourg, Switzerland; Atena-Bianca.Solea@hefr.ch (A.B.S.); \\ ivan.cornu@master.hes-so.ch (I.C.); aurelien.crochet@unifr.ch (A.C.); Christophe.Allemann@hefr.ch (C.A.) \\ 2 Department of Chemistry, University of Fribourg, Chemin du Musée 9, CH-1700 Fribourg, \\ Switzerland; katharina.fromm@unifr.ch \\ 3 Bulgarian Academy of Sciences, Institute of Organic Chemistry with Centre of Phytochemistry, Acad. G. \\ Bonchev street, bl. 9, 1113 Sofia, Bulgaria; vdeneva@orgchm.bas.bg (V.D.); Lantonov@orgchm.bas.bg (L.A.) \\ * Correspondence: olimpia.mamulasteiner@hefr.ch
}

Received: 25 November 2019; Accepted: 27 December 2019; Published: 11 January 2020

\begin{abstract}
Two novel pinene-type ligands have been synthesized and their tautomeric and self-associating behavior studied in solution and in the solid state. The first ligand, an acetylated derivative of 5,6-pinene-bipyridine, displays keto-enol tautomerism in solution. This tautomeric equilibrium was studied by NMR and UV-Vis spectroscopy in various solvents, and the results were compared with the ones obtained through DFT calculations. The second ligand was obtained by an unusual oxidation of the phenanthroline unit of a pinene-phenanthroline derivative. This compound exists as a single tautomer in solution and aggregates both in solution (as observed by NMR) and in the solid state through H-bonding as observed by X-ray structure determination and confirmed by DFT studies.
\end{abstract}

Keywords: tautomerism; pinene derivatives; chiral ligands; molecular spectroscopy; theoretical description; keto-enol tautomerism; H-bonding

\section{Introduction}

Ligands with an annellated pinene backbone have been used extensively for chiral induction in coordination compounds of $d$ and $f$ metal ions, giving rise to well defined, enantiopure supramolecular structures [1-5]. Their ability to control the metal centers' chirality makes them attractive not only in the field of supramolecular chemistry [2], but also for various applications like enantioselective catalysis or single chiral molecular magnets [6-9]. Among the pinene containing ligands, the most studied ones possess a bipyridine unit connected to the pinene moiety through either the 4,5 or 5,6 carbon atoms on the pyridine ring. These ligands can be obtained through a facile and scalable synthesis utilizing a Kröhnke salt as the intermediate [10]. An important and useful feature of these ligands is the facile deprotonation of the methylene unit close to the nitrogen atom of the pyridine ring. Moreover, due to steric effects, the deprotonation proceeds stereoselectively in the presence of strong bases like lithium diisopropylamide (LDA), rendering the diastereoselective functionalization of these ligands possible [11]. There are examples of pinene units functionalized with alkyl [12,13], carboxyl [11], or alcohol groups [14], among others. Another important class of ligands derived from pinene are the so-called CHIRAGEN (chiral generators) ligands, which have two bridged 5,6- or 
4,5-pinene-bipyridine units $[15,16]$. These CHIRAGEN ligands can also predetermine the chirality of the metal centers [17-19].

The pinene-type ligands based on 1,10-phenantroline units $[7,20,21]$ have been less studied than the ligands mentioned above, because their synthesis is more difficult and the rigidity of the phenanthroline unit narrows down their abilities to form discrete (supramolecular) species. Within the small family of 2,3-pinene-1,10-phenantroline ligands, so far only alkyl functionalization of the pinene unit has been reported to this date by Chelucci and co-workers [7,20,21].

Here, we report the synthesis of two new pinene-type ligands based on 2,2'-bipyridine and 1,10-phenanthroline units, as well as the study of their tautomeric behavior. The acetyl functionalized 5,6-pinene-bipyridine Compound 3 features a keto-enol tautomerism. The second ligand, $\mathbf{6}$, obtained by the oxidation of the phenanthroline unit, exists in solution as a single tautomer, which forms dimers by H-bonding. The keto-enol and monomer-dimer equilibria have been investigated by variable temperature (VT) NMR and UV-Vis measurements and the results confirmed by DFT calculations and X-ray studies. To the best of our knowledge, this is the first tautomeric study of pinene containing compounds.

\section{Results and Discussion}

The 5,6-pinene-bipyridine derivative 3 (Scheme 1) was obtained from the $(-)-(R, R)-5,6-$ pinene-bipyridine $\mathbf{1}$, which was synthetized as reported in the literature [10]. Deprotonation of $\mathbf{1}$ and reaction with acetaldehyde gave an $R R S / R R R$ mixture of diastereomers (ratio 2:1) of Compound 2 (Figure S4). The preferred $S$ configuration of the newly formed chiral carbon center was due to the steric hindrance of the pinene unit. Swern oxidation of $\mathbf{2}$ gave the desired Compound $\mathbf{3}$.

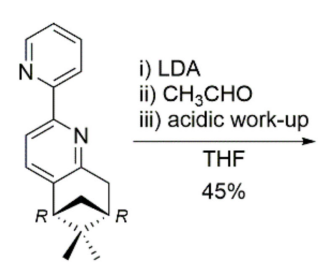

1

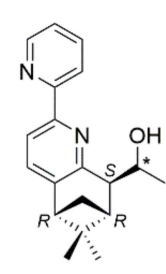

2

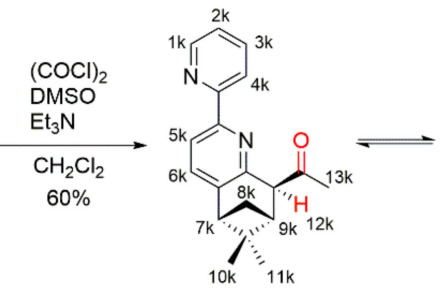

$(R, R, S)-3 k$

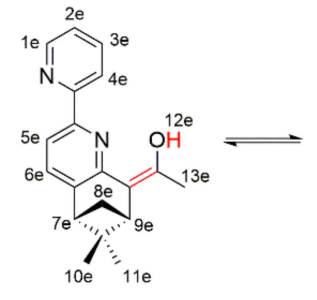

3e

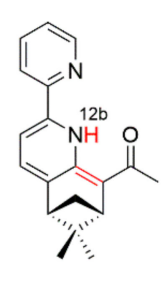

3b

Scheme 1. Synthesis of 3 and its tautomeric forms. LDA, lithium diisopropylamide.

The 5,6-pinene-bipyridine derivative 3 had three different tautomeric forms (keto, enol, and base $\mathrm{NH}$, correspondingly $\mathbf{k}, \mathbf{e}$, and $\mathbf{b}$ ) as shown in Scheme 1 . According to the theoretical calculations (Figure 1), the keto and enol tautomers could co-exist in comparable amounts in $\mathrm{CHCl}_{3}$, $\mathrm{CH}_{2} \mathrm{Cl}_{2}$, and $\mathrm{CH}_{3} \mathrm{CN}$. The corresponding theoretically predicted relative energies of the keto (3k) and enol (3e) tautomers are summarized in Table 1. A similar tautomeric preference has been observed by Gawinecki et al. [22] in 1-phenyl-2-(pyridin-2-yl)ethan-1-one, where structural similarity with 3 in the tautomeric backbone exists. The tautomer $3 \mathbf{b}$ could not be observed in solution as its relative energy exceeded $4 \mathrm{kcal} / \mathrm{mol}$. The stabilization of $\mathbf{3 k}$ and $3 \mathbf{e}$ over $\mathbf{3} \mathbf{b}$ was not surprising. The expected additional stabilization in $\mathbf{3 b}$ through $\mathrm{NH}$... N-bonding was weak because a five membered cycle was formed, and the orientation of the nitrogen atoms led to steric hindrance between the $\mathrm{C} 4$ and $\mathrm{C} 5$ protons. The strength of the resonant assisted hydrogen bonding in $\mathbf{3 e}$ and $\mathbf{3 b}$, estimated as the energy difference with corresponding anti $\mathrm{CHO}$ and $\mathrm{COH}$ isomers, was estimated as 8.7 and 6.7 $\mathrm{kcal} / \mathrm{mol}$, respectively. 


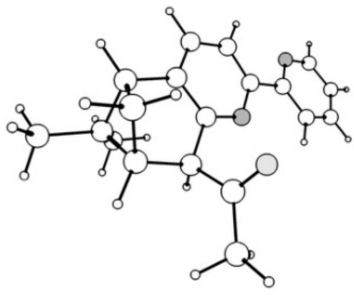

$0.06 \mathrm{kcal} / \mathrm{mol}$

$3.9 \mathrm{D}$

3k

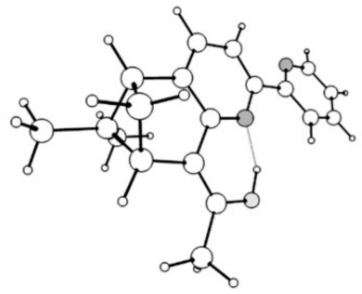

$0 \mathrm{kcal} / \mathrm{mol}$

$1.5 \mathrm{D}$

$3 e$

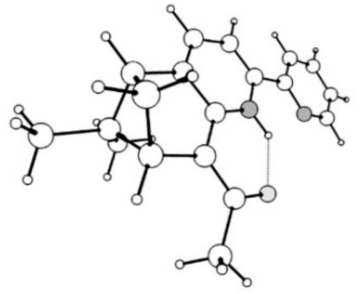

$4.7 \mathrm{kcal} / \mathrm{mol}$

$6.1 \mathrm{D}$

3b

Figure 1. Optimized structures of the tautomers of $\mathbf{3 k}, \mathbf{3 e}$, and $\mathbf{3 b}$ in $\mathrm{CHCl}_{3}$ with the relative energies to $3 \mathbf{k}$ and their dipole moments.

Table 1. Relative energies $\Delta \mathrm{E}$ (from the theoretical calculations) and free energies $\Delta \mathrm{G}^{\circ}$ (from ${ }^{1} \mathrm{H}-\mathrm{NMR}$ spectra) of the tautomer $3 \mathbf{k}$ relative to $3 \mathbf{e}$ in various solvents. A positive value indicates that the keto form is more stable.

\begin{tabular}{|c|c|c|}
\hline Solvent & Theoretical $\Delta \mathrm{E}(\mathrm{kcal} / \mathrm{mol})$ & Experimental $\Delta \mathrm{G}^{\circ}(\mathrm{kcal} / \mathrm{mol})$ \\
\hline $\mathrm{CD}_{3} \mathrm{CN}$ & 0.84 & 0.15 \\
\hline $\mathrm{CD}_{2} \mathrm{Cl}_{2}$ & 0.37 & 0.28 \\
\hline $\mathrm{CDCl}_{3}$ & -0.06 & 0.19 \\
\hline decalin- $d 18$ & -0.82 & -0.46 \\
\hline
\end{tabular}

Theoretical calculations showed that $3 \mathbf{k}$ and $3 \mathbf{e}$ had almost the same energy. As a consequence, both tautomers should be detected in solution. UV-Vis spectra showed two major long wavelength bands in all solvents (Figure S3). The intensive composite band around $290 \mathrm{~nm}$ belonged to 3k according to the theoretical calculations (two sub-bands at 290 and $285 \mathrm{~nm}$ with oscillator strengths of 0.54 and 0.11 resp. in acetonitrile) along with a red shifted shoulder at $\sim 350 \mathrm{~nm}$, attributed to $3 \mathbf{e}$ (368 nm, oscillator strength 0.13). The different dipole moments of the tautomers suggested that the equilibrium was solvent dependent. Moreover, modifying the solvent caused light spectral changes that could be attributed to the substantial difference in the intensities of the bands and to the strong overlapping between them. This overlap did not allow a quantitative interpretation of the equilibrium.

Due to the fact that the current keto-enol tautomerism was accompanied by substantial structural rearrangement, it was slow on the NMR timescale. As a result, two sets of signals corresponding to the tautomers were obtained in various deuterated solvents, such as decalin- $d 18, \mathrm{CD}_{2} \mathrm{Cl}_{2}, \mathrm{CDCl}_{3}$, and $\mathrm{CD}_{3} \mathrm{CN}$ (Figure 2 and Figures S12-S14). In $\mathrm{CD}_{3} \mathrm{CN}$, the characteristic signal H12e belonging to the $\mathrm{OH}$ group of the enol form $3 \mathbf{e}$ appeared at $14.30-14.50 \mathrm{ppm}$, whereas the signal characteristic of the keto form (H12k) appeared at around $4.30 \mathrm{ppm}$ (Figure 2). The ${ }^{1} \mathrm{H}-\mathrm{NMR}$ shifts of the two signals (H12k and H12e) were in good agreement with the calculated ones. Considering the H-bond with the $\mathrm{N}$ atom of the pyridine unit, values of $4.66 \mathrm{ppm}$ for H12k and $14.16 \mathrm{ppm}$ for H12e were obtained. The slight deviation observed for $\operatorname{H1} 12 \mathrm{k}(\Delta=0.36 \mathrm{ppm})$ could indicate a rotation around the single bond, which would shift the proton upfield, as observed experimentally. For instance, according to the calculations, the $\mathbf{3 k}$ tautomer existed as two stable isomers with near energies (rotation around the single OC-CH12k-bond) where the ${ }^{1} \mathrm{H}$ shift of $\mathrm{H} 12 \mathrm{k}$ varied from 4.10 to $4.66 \mathrm{ppm}$. In the VT ${ }^{1} \mathrm{H}-\mathrm{NMR}$ spectra, the shift of the H12e proton changed. As the temperature increased from 298 to $348 \mathrm{~K}$, the signal shift decreased by $0.07 \mathrm{ppm}$, indicating the weakening of the $\mathrm{O}-\mathrm{H}-$-bond with temperature (Figure 2). The keto form 3k was also proven experimentally by the presence of a signal at $210 \mathrm{ppm}$ $(\mathrm{C}=\mathrm{O})$ in the ${ }^{13} \mathrm{C}-\mathrm{NMR}$ spectrum (Figure $\mathrm{S} 9$ ). 


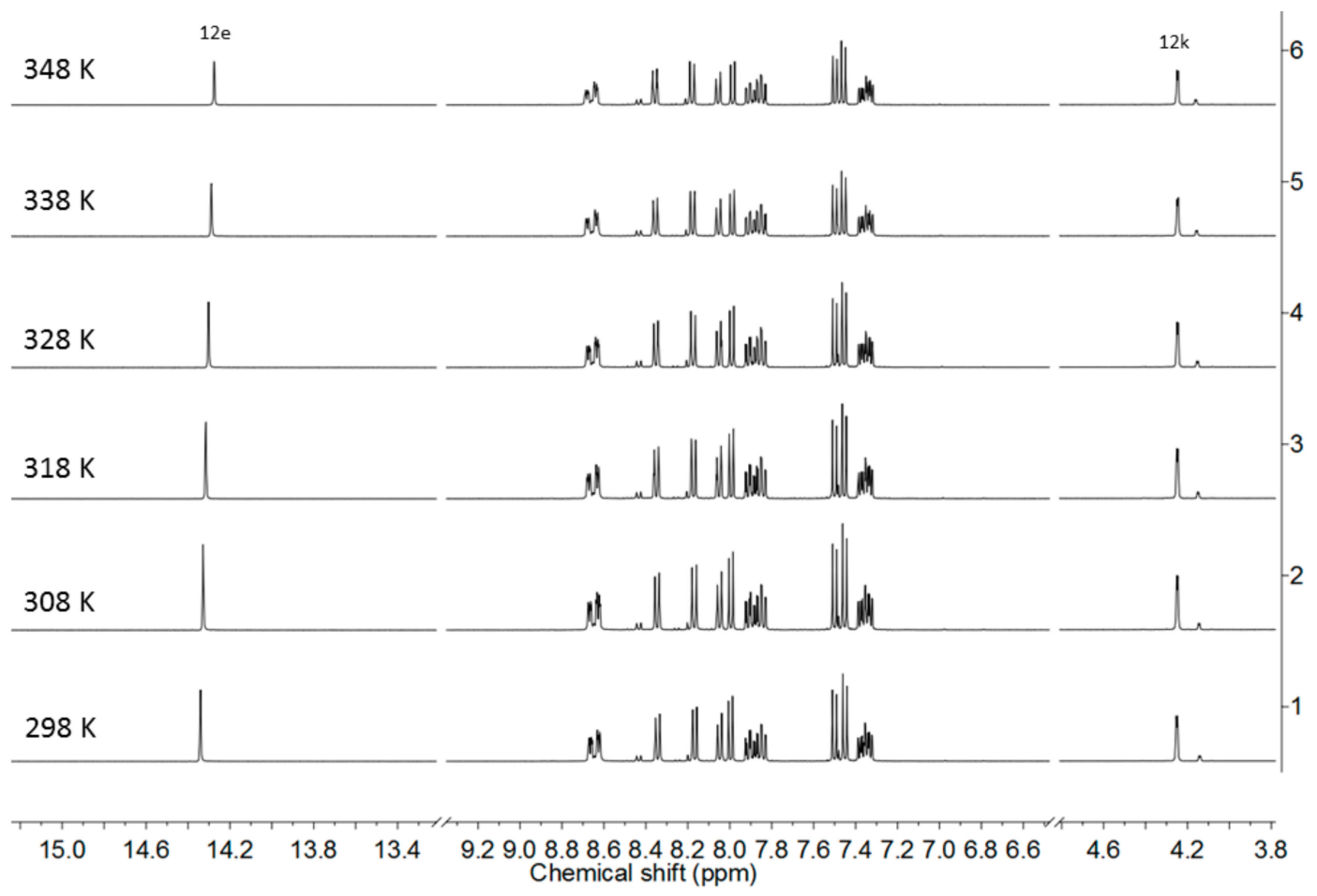

Figure 2. High shift region of the variable temperature (VT) ${ }^{1} \mathrm{H}-\mathrm{NMR}$ spectra of Compound 3 in $\mathrm{CD}_{3} \mathrm{CN}$.

The existence of two distinct sets of ${ }^{1} \mathrm{H}-\mathrm{NMR}$ signals for $3 \mathbf{e}$ and $\mathbf{3 k}$ allowed a quantitative estimation of the tautomeric ratio, allowing evaluation of the equilibrium constant $\mathrm{K}_{\mathrm{T}}=$ [enol]/[keto] and of the Gibbs free energy $\left(\Delta \mathrm{G}^{\circ}\right)$, enthalpy $\left(\Delta \mathrm{H}^{\circ}\right)$, and entropy $\left(\Delta \mathrm{S}^{\circ}\right)$ values. Depending on solvent polarity, different $\Delta G^{\circ}$ values were obtained (Table 1). The relative stability of the two forms seemed to be influenced by solvent polarity, as well as water content (Figure S1). The less polar enol 3e was favored in less polar solvents, while the presence of water favored the keto form $3 \mathbf{k}$ through intermolecular $\mathrm{H}$-bond formation between the free carbonyl group of $3 \mathbf{k}$ and water. By plotting $\Delta \mathrm{G}^{\circ}=$ $\Delta \mathrm{H}^{\circ}-\mathrm{T} \Delta \mathrm{S}^{\circ}$ (Figure S2), the $\Delta \mathrm{H}^{\circ}$ and $\Delta \mathrm{S}^{\circ}$ could also be calculated in $\mathrm{CD}_{3} \mathrm{CN}$. The obtained values were $-0.83 \mathrm{kcal} / \mathrm{mol}$ for $\Delta \mathrm{H}^{\circ}$ and $-0.003 \mathrm{kcal} / \mathrm{mol} \cdot \mathrm{K}$ for $\Delta \mathrm{S}^{\circ}$. This clearly indicated that the equilibrium 3k-3e was mainly enthalpy driven. Thus, a temperature decrease favored the enol form $\mathbf{3 e}$.

The data in Table 1 show a reasonable agreement between theory and experiment. The tautomeric equilibrium was correctly predicted by theoretical calculations. Moreover, the decrease in the solvent polarity led to destabilization of the more polar $3 \mathbf{k}$, as expected. The only deviation observed was the relative order of experimentally determined values of $\Delta \mathrm{G}^{\circ}$ in $\mathrm{CD}_{3} \mathrm{CN}$ and chlorinated solvents. It seemed that the more polar keto tautomer was better stabilized by the less polar (compared to $\left.\mathrm{CD}_{3} \mathrm{CN}\right) \mathrm{CD}_{2} \mathrm{Cl}_{2}$ and $\mathrm{CDCl}_{3}$. The chlorinated solvents were in fact strong proton donor solvents; thus, the keto tautomer $3 \mathbf{k}$ could be more favored through intermolecular $\mathrm{H}$-bonding involving the free carbonyl group, as reported in other tautomeric systems [23,24].

The second studied compound, pinene-phenanthroline-methylene-carboxylate 6, was obtained in two steps from Compound 4 [7]. Deprotonation of 4 followed by an alkylation with allyl bromide gave the intermediate 5 (Scheme 2 and Figures S15 and S16). This intermediate 5 was subsequently oxidized with $\mathrm{KMnO}_{4}$. To our surprise, besides the oxidation of the allyl unit to the carboxylic acid, the phenanthroline moiety was also oxidized. This was a rather unusual oxidation, as most of the oxidations of the 1,10-phenantroline affected the $\mathrm{CH}$ groups from the central condensed cycle [25]. 


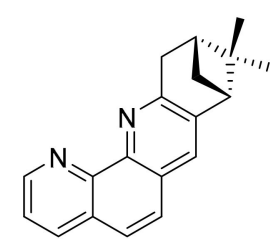

4

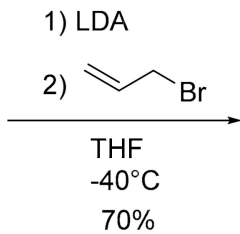

$70 \%$<smiles>C=CC[C@H]1c2nc3c(ccc4cccnc43)cc2C2CC1C2(C)C</smiles>

5

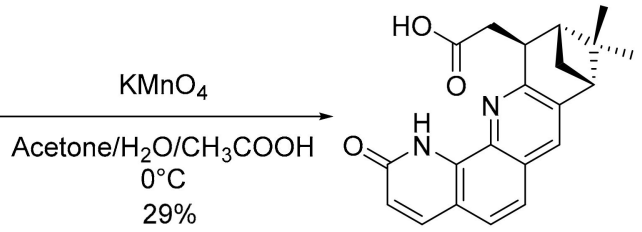

6

Scheme 2. Synthetic pathway for 6 .

The theoretical calculations predicted that the other tautomeric forms of the 6 were substantially less stable compared with the tautomeric form observed experimentally (Scheme 2 and Table S1). This stabilization, being typical for 2- and 4-hydroxy-1,10- phenanthroline, was a result of the formed intramolecular hydrogen N ... H-N-bonding [26,27].

During the oxidation process, the aromaticity of one condensed cycle was broken in Compound $\mathbf{6}$, as depicted in Scheme 2. Due to the presence of lactam and carboxylic acid moieties, the compound aggregated, as observed through UV-Vis spectroscopy (Figure 3 and Figure S4) and ${ }^{1} \mathrm{H}-\mathrm{NMR}$ spectroscopy $(\mathrm{S} 17, \mathrm{~S} 18)$. In the UV-Vis spectra in DMSO, the band at $\sim 290 \mathrm{~nm}$ lowered with dilution, while the long wavelength peak showed little change. The spectra in can were featured in the same way, which indicated that there was no substantial solvent effect. According to the NMR data, the dimerization took place through intermolecular H-bonding between the amide group and the carboxylic unit from a neighboring molecule forming a cyclic structure. At $300 \mathrm{~K}$, in the ${ }^{1} \mathrm{H}-\mathrm{NMR}$ spectrum in DMSO- $d 6$, the proton signal from the $\mathrm{COOH}$ appeared at $12.24 \mathrm{ppm}$, while the one of the $\mathrm{NH}$ group appeared at $11.55 \mathrm{ppm}$ (Figure 3 and Figure S19). When the temperature was increased, the signal corresponding to the $\mathrm{COOH}$ unit disappeared, while the $\mathrm{NH}$ signal broadened and shifted upfield to $10.73 \mathrm{ppm}$. These observations showed that a temperature increase broke the H-bonds, which led to the formation of the monomeric form.
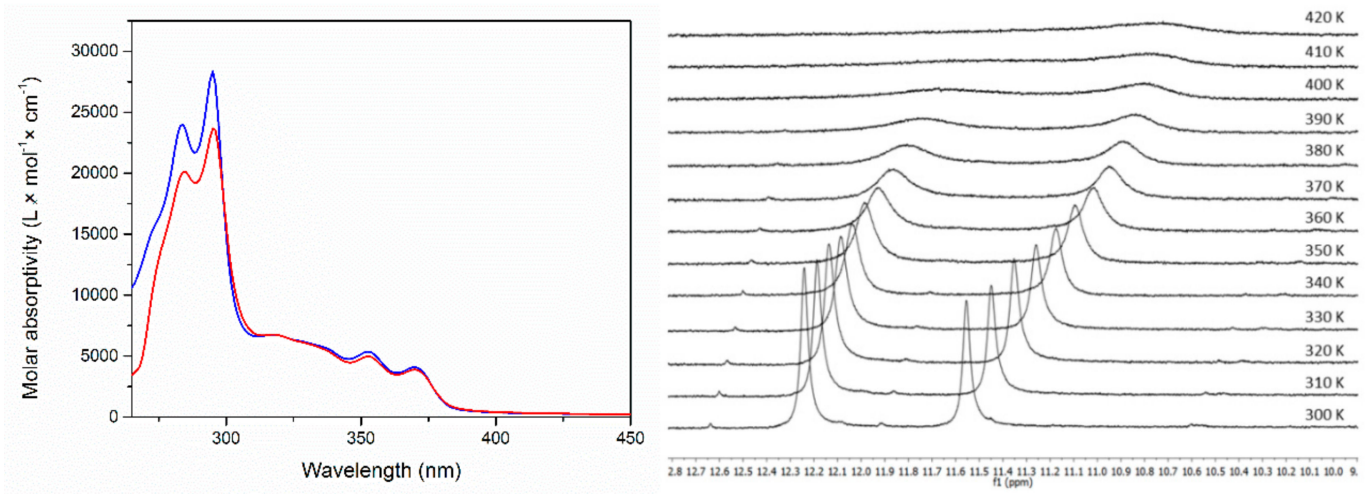

Figure 3. Left: Absorption spectra of 6 in DMSO as a function of the concentration while keeping the product between the concentration value and the path length constant $\left(5.0 \times 10^{-5} \mathrm{M}\right)$. The concentrations are as follows: blue solid line: $5.0 \times 10^{-4} \mathrm{M}$ (most concentrated); red solid line: $5.0 \times 10^{-6} \mathrm{M}$ (most diluted). Right: High shift region from variable temperature ${ }^{1} \mathrm{H}-\mathrm{NMR}$ spectra of Compound $\mathbf{6}$, in DMSO-d6.

This was in a good agreement with the theoretical calculations showing that the most stable dimer of Compound 6 was the asymmetric one, formed through interaction between $\mathrm{COOH}$ and $\mathrm{CONH}$ groups (Figure 4). Moreover, it was also in an excellent agreement with the X-ray structure (Figure 5) where a helical-like arrangement of the molecules connected via intermolecular H-bonds between the carboxylic and amido moieties was observed (Figure 6). This type of aggregate explained the observed spectral changes. According to the predicted spectra of the monomer and dimer (Table S2), there was little difference between the long wavelength bands both as position and intensity. 
Therefore, the dilution did not lead to substantial changes in the 310-400 $\mathrm{nm}$ region. However, the intensity of the band around $290 \mathrm{~nm}$ was substantially large in the dimer, which led to the rise of this band upon the concentration rise. The predicted ${ }^{1} \mathrm{H}-\mathrm{NMR}$ shifts for the protons involved in the H-bonding in the dimer were $14.0(\mathrm{NH})$ and $15.5 \mathrm{ppm}(\mathrm{COOH})$, while those of a single molecule should be $6.71(\mathrm{COOH})$ and $10.25 \mathrm{ppm}(\mathrm{NH})$. The difference between the calculated shifts assuming that solely dimers were formed and those experimentally measured by ${ }^{1} \mathrm{H}-\mathrm{NMR}$ indicated that the actual aggregation in solution was more complicated and probably led to the formation of higher order aggregates. This corroborates the unusually high value of the specific rotation $[\alpha]_{\mathrm{D}}^{20}=+359$ $\mathrm{deg} \cdot \mathrm{cm}^{3} \cdot \mathrm{dm}^{-1} \cdot \mathrm{g}^{-1}$ measured for the molecule 6 . Indeed, such high specific rotation can be due to the Horeau effect, which arises when chiral molecules aggregate in solution, forming supramolecular species with higher rotatory power than the monomers [28].

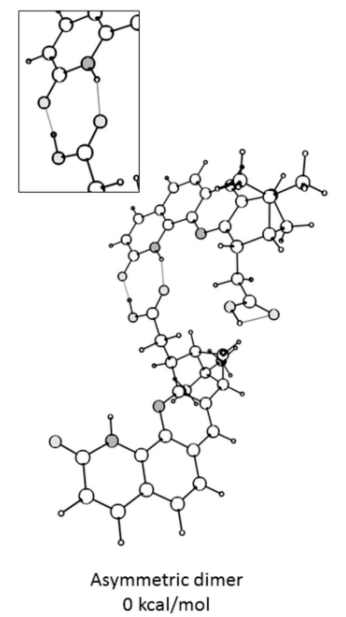

$0 \mathrm{kcal} / \mathrm{mol}$
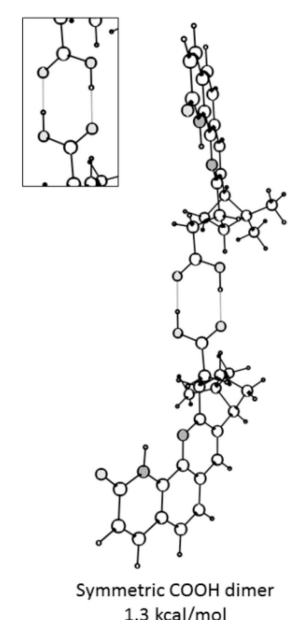

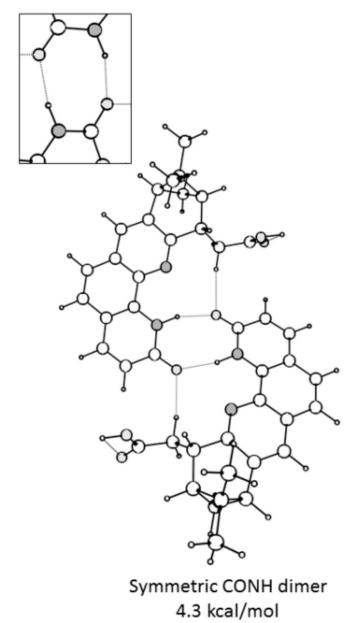

$4.3 \mathrm{kcal} / \mathrm{mol}$

Figure 4. Possible dimers of 6 in DMSO with their relative energies estimated without counterpoise corrections. The differences in the gas phase with counterpose correction are as follows: $0,1.5$ and $2.5 \mathrm{kcal} / \mathrm{mol}$.

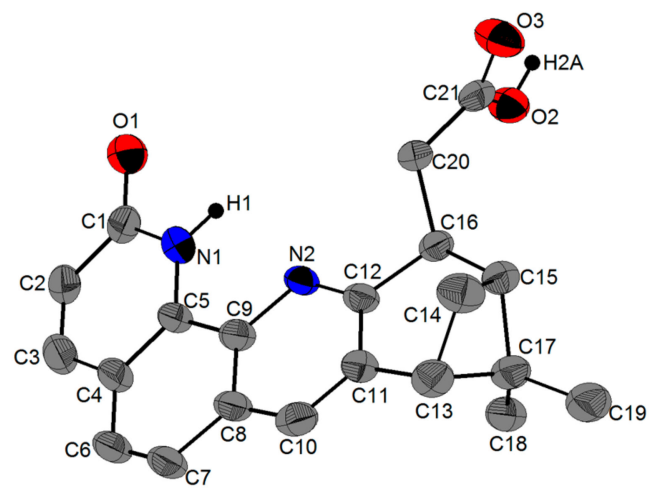

Figure 5. View of the molecular structure of $\mathbf{6}$ as determined by single crystal X-ray diffraction, at $30 \%$ probability. The $\mathrm{H}$ atoms connected to carbon atoms have been removed for clarity. 


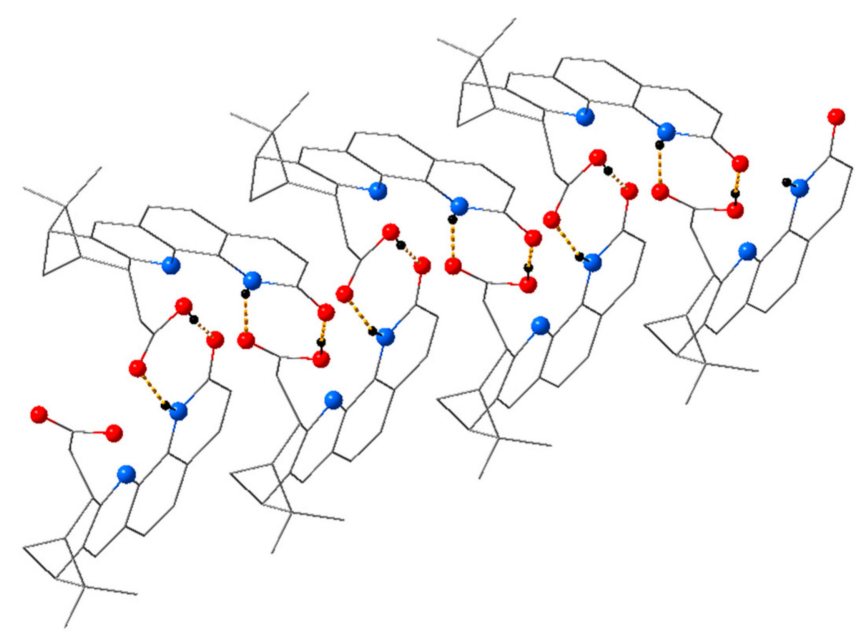

Figure 6. Hydrogen bonding pattern in the solid state structure of 6 .

\section{Single Crystal X-Ray Diffraction Studies}

Compound 6 crystallized in the space group $P 2_{1} 2_{1} 2_{1}\left(\mathrm{~N}^{\circ} 19\right)$ with one molecule in the asymmetric unit. The solid state structure of $\mathbf{6}$ was in good agreement with the solution data as well. Only the lactam tautomer drawn in Scheme 2 was present in the solid state, as shown by the $\mathrm{C}-\mathrm{N}$ and $\mathrm{C}-\mathrm{O}$ bond lengths. In the lactam ring, the $\mathrm{C} 1-\mathrm{C} 2$ - and C3-C4-bonds had lengths of 1.426(10) $\AA$ and 1.430(11) $\AA$, respectively, which were typical for single $\mathrm{C}-\mathrm{C}$ bonds. The $\mathrm{C} 2-\mathrm{C} 3-$ and $\mathrm{C} 4-\mathrm{C} 5$-bonds showed a double bond character, with lengths of 1.333(11) $\AA$ and 1.386(9) $\AA$, respectively. The C1-O1-bond also showed a double bond character with a bond length of 1.274(9) $\AA$.

Each molecule was interacting with a neighboring molecule through $\mathrm{H}$-bonding between the lactam moiety and the carboxylic unit, forming a $R_{2}^{2}(8)$ motif. The ring constraint forced the lactam unit into the cis configuration necessary for such a type of H-bonding pattern. The $\mathrm{O} 1 \cdots \mathrm{H} 2 \mathrm{~A}-\mathrm{O} 2$ distance was $1.782(6) \AA$, and the $\mathrm{O} 1-\mathrm{H} 2 \mathrm{~A}-\mathrm{O} 2$ angle was $171.2^{\circ}$, while the $\mathrm{N} 1-\mathrm{H} 1 \cdots \mathrm{O} 3$ distance measured 2.045(6) $\AA$, with an angle $\mathrm{N} 1-\mathrm{H} 1-\mathrm{O} 3$ of $160.2^{\circ}$. These distances and angles indicated a moderately strong H-bond [29]. The intermolecular H-bonds led to a helical, screw-like arrangement of the molecules in the crystal, as shown in Figure 6.

\section{Materials and Methods}

\subsection{General}

If inert conditions were needed, the reactions were performed under a nitrogen atmosphere using oven dried glassware $\left(120^{\circ} \mathrm{C}\right)$. Analytical thin layer chromatography (TLC) was performed on $\mathrm{SiO}_{2}$ plates GF254 (0.25 mm layer thickness). Flash chromatography purifications were performed on a CombiFlash EZ Prep from Teledyne. ${ }^{1} \mathrm{H}-\mathrm{NMR}$ and ${ }^{13} \mathrm{C}-\mathrm{NMR}$ spectra were recorded on Bruker Avance DPX 300 and Bruker Avance $400 \mathrm{MHz}$ spectrometers, using TMS or the residual solvent proton as the internal standard. Coupling constants are reported in Hz. (+)-ESI-MS spectra were recorded on the Bruker FT-MS 4.7T Bio Apex II instrument.

\subsubsection{Single Crystal X-Ray Diffraction of 6}

Colorless needle shaped single crystals of $\mathbf{6}$ were recrystallized from acetone by slow evaporation. A suitable crystal of size $0.32 \times 0.14 \times 0.02 \mathrm{~mm}^{3}$ was selected and mounted on a mylar loop in oil on a Stoe IPDS2 diffractometer. The crystal was kept at a steady $T=250(2) \mathrm{K}$ during data collection. The structure was solved with the ShelXT [30] structure solution program using the Intrinsic Phasing solution method and by using Olex2 [31] as the graphical interface. The model was refined with Version 2017/1 of ShelXL [32] using least squares minimization. CCDC 1,958,303 
contains the supplementary crystallographic data for $\mathbf{6}$. These data can be obtained free of charge via http://www.ccdc.cam.ac.uk/conts/retrieving.html, or from the Cambridge Crystallographic Data Centre, 12 Union Road, Cambridge CB2 1EZ, U.K.; fax: (+44) 1223-336-033; or e-mail: deposit@ccdc.cam.ac.uk.

The starting materials were purchased from Sigma-Aldrich, Fluka, or Acros Organics and used without further purification, unless stated otherwise. 1 [10] and 4 [7] were synthesized as previously reported in the literature, starting from $81 \%$ ee pinocarvone.

\subsubsection{Synthesis of 2}

Under inert atmosphere, anhydrous THF $(15 \mathrm{~mL})$ and diisopropylamine $(0.38 \mathrm{~mL}, 2.65 \mathrm{mmol}$, $1.325 \mathrm{eq})$ were added into a two neck flask and subsequently cooled to $0{ }^{\circ} \mathrm{C}$. Over this, $\mathrm{nBuLi}(1.15 \mathrm{~mL}$, $2.5 \mathrm{mmol}, 1.25 \mathrm{eq}, 2.2 \mathrm{M}$ solution in hexane) was added dropwise. The solution was stirred at this temperature for 10 minutes and afterwards cooled to $-40^{\circ} \mathrm{C}$. A solution of (-)-5,6-pinene-bipyridine $(500 \mathrm{mg}, 2 \mathrm{mmol}, 1 \mathrm{eq})$ in dry THF $(8 \mathrm{~mL})$ was added dropwise. The dark blue solution was stirred at $-40{ }^{\circ} \mathrm{C}$ for $2 \mathrm{~h}$. $\mathrm{CH}_{3} \mathrm{CHO}(0.17 \mathrm{~mL}, 3.0 \mathrm{mmol}, 1.5 \mathrm{eq})$ was then added, and the solution was allowed to warm to room temperature and afterwards stirred for an additional $30 \mathrm{~min}$. The obtained light brown mixture was quenched with $\mathrm{HCl}(0.3 \mathrm{~mL}, 1 \mathrm{M})$. The solvent was evaporated under reduced pressure, and the residue was dissolved in $\mathrm{CH}_{2} \mathrm{Cl}_{2}(30 \mathrm{~mL})$. The mixture was washed with water $(3 \times 10 \mathrm{~mL})$, and the collected organic phases were dried over anhydrous $\mathrm{MgSO}_{4}$. The solvent was removed under reduced pressure, and the obtained oil was further purified by column chromatography on silica gel using n-hexanes: $\mathrm{Et}_{2} \mathrm{O}: \mathrm{Et}_{3} \mathrm{~N}(4: 1.5: 0.25)$ as the eluent. Compound $2(\mathrm{Rf}=0.4)$ was obtained as a light yellow oil $(0.25 \mathrm{~g}$, yield $45 \%) .{ }^{1} \mathrm{H}-\mathrm{NMR}\left(300 \mathrm{MHz}, \mathrm{CDCl}_{3}\right) \delta=8.66(\mathrm{~m}, 1 \mathrm{H}, \mathrm{H} 1), 8.20(\mathrm{~m}, 2 \mathrm{H}, \mathrm{H} 4, \mathrm{H} 5)$, $7.77(\mathrm{~m}, 1 \mathrm{H}, \mathrm{H} 3), 7.43(\mathrm{~d}, J=7.8 \mathrm{~Hz}, 1 \mathrm{H}, \mathrm{H} 6), 7.31-7.27(\mathrm{~m}, 1 \mathrm{H}, \mathrm{H} 2), 7.22(\mathrm{~s}, 1 \mathrm{H}, \mathrm{OH}), 4.36(\mathrm{~m}, 1 \mathrm{H}$, H12B), 4.09 (m, 1H, H12A), 3.11 (dd, $J=9.5,2.4 \mathrm{~Hz}, 1 \mathrm{H}, \mathrm{H} 9 \mathrm{~B}), 2.94(\mathrm{dd}, J=9.3,2.5 \mathrm{~Hz}, 1 \mathrm{H}, \mathrm{H} 9 \mathrm{~A})$, 2.88-2.73 (m, 3H, H14A, H14B, H7B), 2.60 (dt, $J=10.0,5.7 \mathrm{~Hz}, 1 \mathrm{H}, \mathrm{H} 8 \mathrm{Aa}), 2.54$ (td, $J=6.2,2.4 \mathrm{~Hz} 1 \mathrm{H}$, H8Ba), $2.36(\mathrm{td}, J=6.0,2.5 \mathrm{~Hz}, 1 \mathrm{H}, \mathrm{H} 7 \mathrm{~A}), 1.45(\mathrm{~s}, 3 \mathrm{H}, \mathrm{H} 10 \mathrm{~A}), 1.44(\mathrm{~s}, 3 \mathrm{H}, \mathrm{H} 10 \mathrm{~B}), 1.42(\mathrm{~d}, J=8.9 \mathrm{~Hz}, 1 \mathrm{H}$, $\mathrm{H} 8 \mathrm{Bb}), 1.35(\mathrm{~d}, J=9.9 \mathrm{~Hz}, 1 \mathrm{H}, \mathrm{H} 8 \mathrm{Ab}), 1.31$ (d, $J=6.1 \mathrm{~Hz}, 3 \mathrm{H}, \mathrm{H} 13 \mathrm{~B}), 1.30(\mathrm{~d}, J=6.1 \mathrm{~Hz}, 3 \mathrm{H}, \mathrm{H} 13 \mathrm{~A})$, 0.70 (s, 3H, H11B), 0.69 (s, 3H, H11A). ${ }^{13} \mathrm{C}-\mathrm{NMR}\left(75 \mathrm{MHz}, \mathrm{CDCl}_{3}\right) \delta=159.13,158.82,155.77,155.71$, $152.48,149.33,142.66,142.05,137.16,134.76,134.64,123.61,123.60,120.66,119.03,118.99,69.59,69.23$, $55.05,50.15,47.06,46.91,43.38,42.44,41.46,39.55,33.76,28.92,26.91,26.34,24.13,21.29,21.10,21.09$. $[\alpha]_{\mathrm{D}}^{20}=-5.3 \mathrm{deg} \cdot \mathrm{cm}^{3} \cdot \mathrm{dm}^{-1} \cdot \mathrm{g}^{-1}\left(\mathrm{c} 0.184 \mathrm{~g} / \mathrm{L}, \mathrm{CH}_{2} \mathrm{Cl}_{2}\right)$. ESI-MS (+): $295.1[\mathrm{M}+\mathrm{H}]^{+}$and $317.0[\mathrm{M}+\mathrm{Na}]^{+}$. HRMS (ESI) calcd. for $\mathrm{C}_{19} \mathrm{H}_{23} \mathrm{H}_{2} \mathrm{O}^{+}[\mathrm{M}+\mathrm{H}]^{+}$295.1805, found 295.1793 .

\subsubsection{Synthesis of 3}

Under inert atmosphere, $(\mathrm{COCl})_{2}(0.75 \mathrm{~mL}, 8.56 \mathrm{mmol}, 1.4 \mathrm{eq})$ was dissolved in $\mathrm{CH}_{2} \mathrm{Cl}_{2}(45 \mathrm{~mL})$. The solution was cooled to $-78{ }^{\circ} \mathrm{C}$. DMSO $(1.30 \mathrm{~mL}, 17.12 \mathrm{mmol}, 2.8 \mathrm{eq})$ was added dropwise. The solution was stirred at this temperature for $15 \mathrm{~min}$. A solution of $\mathbf{1}(1.80 \mathrm{~g}, 6.114 \mathrm{mmol}, 1 \mathrm{eq})$ in anhydrous $\mathrm{CH}_{2} \mathrm{Cl}_{2}(45 \mathrm{~mL})$ was added dropwise. The reaction mixture was allowed to reach room temperature and stirred for $2.5 \mathrm{~h}$. Then, the solvent was evaporated under reduced pressure. EtOAc (100 mL) was added, followed by a saturated solution of $\mathrm{Na}_{2} \mathrm{CO}_{3}(75 \mathrm{~mL})$. The organic phase was washed with brine and dried over $\mathrm{Na}_{2} \mathrm{SO}_{4}$. The solvent was evaporated under reduced pressure, and the residue was purified by column chromatography on silica gel, using n-hexane:EtOAc (4:0.5) as the eluent. Compound $3(1.08 \mathrm{~g}, 60 \%$ yield, $\mathrm{Rf}=0.2)$ was obtained as an orange oil. ${ }^{1} \mathrm{H}-\mathrm{NMR}\left(400 \mathrm{MHz}, \mathrm{CD}_{3} \mathrm{CN}\right)$ $\delta=14.34(\mathrm{~m}, 1 \mathrm{H}, \mathrm{H} 12 \mathrm{e}), 8.67(\mathrm{ddd}, J=4.8,1.8,1.0 \mathrm{~Hz}, 1 \mathrm{H}, \mathrm{H} 1 \mathrm{k}), 8.63(\mathrm{ddd}, J=4.8,1.8,0.9 \mathrm{~Hz}, 1 \mathrm{H}$, H1e), 8.34 (dt, $J=8.0,1.1 \mathrm{~Hz}, 1 \mathrm{H}, \mathrm{H} 4 \mathrm{k}), 8.17$ (dd, $J=7.8,0.7 \mathrm{~Hz}, 1 \mathrm{H}, \mathrm{H} 5 \mathrm{k}), 8.05$ (dt, J = 8.0, $1.1 \mathrm{~Hz}, 1 \mathrm{H}$, H4e), $8.00(\mathrm{~d}, J=7.7 \mathrm{~Hz}, 1 \mathrm{H}, \mathrm{H} 5 \mathrm{e}), 7.90(\mathrm{td}, J=7.8,1.8 \mathrm{~Hz}, 1 \mathrm{H}, \mathrm{H} 3 \mathrm{e}), 7.85(\mathrm{td}, J=7.9,1.8 \mathrm{~Hz}, 1 \mathrm{H}, \mathrm{H} 3 \mathrm{k})$, $7.50(\mathrm{~d}, J=7.7 \mathrm{~Hz}, 1 \mathrm{H}, \mathrm{H6e}), 7.45(\mathrm{~d}, J=7.8 \mathrm{~Hz}, 1 \mathrm{H}, \mathrm{H} 6 \mathrm{k}), 7.39-7.35(\mathrm{~m}, 1 \mathrm{H}, \mathrm{H} 2 \mathrm{e}), 7.35-7.31(\mathrm{~m}, 1 \mathrm{H}$, $\mathrm{H} 2 \mathrm{k}), 4.25(\mathrm{~d}, J=2.4 \mathrm{~Hz}, 1 \mathrm{H}, \mathrm{H} 12 \mathrm{k}), 3.01(\mathrm{t}, J=6.0 \mathrm{~Hz}, 1 \mathrm{H}, \mathrm{H} 7 \mathrm{e}), 2.95(\mathrm{t}, J=5.8 \mathrm{~Hz}, 1 \mathrm{H}, \mathrm{H} 9 \mathrm{e}), 2.86$ $(\mathrm{t}, J=5.7 \mathrm{~Hz}, 1 \mathrm{H}, \mathrm{H7k}), 2.83-2.76(\mathrm{~m}, 1 \mathrm{H}, \mathrm{H} 8 \mathrm{e}-\mathrm{b}), 2.65(\mathrm{dt}, J=10.0,5.4 \mathrm{~Hz}, 1 \mathrm{H}, \mathrm{H} 8 \mathrm{k}-\mathrm{b}), 2.58-2.54(\mathrm{~m}$, 1H, H9k), 2.43 (s, 3H, H13k), 2.00 (d, J = 0.8 Hz, 3H, H13e), 1.50 (d, J = 10.1 Hz, 1H, H8k-a), 1.47 (s, $3 \mathrm{H}, \mathrm{H} 10 \mathrm{k}), 1.46$ (s, 3H, H10e), 1.31 (d, J = 9.4 Hz, 1H, H8e-a), 0.65 (s, 3H, H11k), 0.62 (s, 3H, H11e). 
${ }^{13} \mathrm{C}-\mathrm{NMR}\left(126 \mathrm{MHz}, \mathrm{CD}_{3} \mathrm{CN}\right) \delta=209.48,158.15,157.04,156.72,155.86,155.18,154.34,150.50,150.15$, $143.72,140.51,138.34,137.93,135.25,134.84,124.65,124.48,121.19,120.71,119.18,118.29,117.35,108.73$, $58.53,48.43,46.74,45.38,44.15,42.85,40.93,32.94,31.39,29.83,26.18,26.11,22.56,21.18,18.14 .[\alpha]_{\mathrm{D}}^{20}=$ $-60 \mathrm{deg} \cdot \mathrm{cm}^{3} \cdot \mathrm{dm}^{-1} \cdot \mathrm{g}^{-1}$ (c $0.100 \mathrm{~g} / \mathrm{L}, \mathrm{CH}_{2} \mathrm{Cl}_{2}$ ). HRMS (ESI) calcd. for $\mathrm{C}_{19} \mathrm{H}_{21} \mathrm{~N}_{2} \mathrm{O}^{+}[\mathrm{M}+\mathrm{H}]^{+} 293.1648$, found 293.1653 .

\subsubsection{Synthesis of 5}

Using the standard Schlenk technique, diisopropylamine $(0.28 \mathrm{~mL}, 2 \mathrm{mmol}, 1.1 \mathrm{eq})$ was added to anhydrous THF $(30 \mathrm{~mL})$ in a $100 \mathrm{~mL}$ Schlenk flask. The solution was cooled to $-40{ }^{\circ} \mathrm{C}$, and a solution of nBuLi (1.6 M, $1.2 \mathrm{~mL}, 1.8 \mathrm{mmol}, 1 \mathrm{eq})$ was added. Compound $4(0.5 \mathrm{~g}, 1.8 \mathrm{mmol}, 1 \mathrm{eq})$ dissolved in anhydrous THF ( $30 \mathrm{~mL}$ ) was added dropwise over $15 \mathrm{~min}$. A very deep red color appeared instantly. This solution was stirred for $1 \mathrm{~h}$ at $-40^{\circ} \mathrm{C}$. Allyl bromide $(0.3 \mathrm{~mL}, 3.6 \mathrm{mmol}, 2$ equiv) was then added, and the cooling bath was removed. Stirring was continued overnight. Methanol $(2 \mathrm{~mL})$ was then added, and the reaction mixture was evaporated and purified on silica gel using $\mathrm{tBuOMe}_{\mathrm{Et}} \mathrm{N} \mathrm{N}(95: 5)$ as the eluent. Compound $5(0.42 \mathrm{~g}, 70 \%$ yield, $\mathrm{Rf}=0.6)$ was obtained as a beige solid. ${ }^{1} \mathrm{H}-\mathrm{NMR}$ : (300 $\left.\mathrm{MHz}, \mathrm{CDCl}_{3}\right) \delta=9.11(\mathrm{dd}, J=4.4,1.7 \mathrm{~Hz}, 1 \mathrm{H}, \mathrm{H} 1), 8.13(\mathrm{dd}, J=8.1,1.7 \mathrm{~Hz}, 1 \mathrm{H}, \mathrm{H} 3), 7.63(\mathrm{~m}, 3 \mathrm{H}, \mathrm{H} 6$, H7, H10), 7.49 (dd, J = 8.1, 4.4 Hz, 1H, H2), 5.92 (m, 1H, H21), 5.02 (m, 2H, H22), 3.50 (m, 2H, H20), 2.94 $(\mathrm{t}, J=5.7 \mathrm{~Hz}, 1 \mathrm{H}, \mathrm{H} 13), 2.55(\mathrm{~m}, 1 \mathrm{H}, \mathrm{H} 14 \mathrm{a}), 2.36(\mathrm{td}, J=6.1,2.4 \mathrm{~Hz}, 1 \mathrm{H}, \mathrm{H} 15), 2.24(\mathrm{~m}, 1 \mathrm{H}, \mathrm{H} 16), 1.4(\mathrm{~s}$, $3 \mathrm{H}, \mathrm{H} 19), 1.36(\mathrm{dd}, J=9.8 \mathrm{~Hz}, 1 \mathrm{H}, \mathrm{H} 14 \mathrm{~b}), 0.25$ (s, 3H, H18). ${ }^{13} \mathrm{C}-\mathrm{NMR}\left(75 \mathrm{MHz}, \mathrm{CDCl}_{3}\right) \delta=161.53$, 150.30, 146.17, 144.43, 142.22, 137.75, 135.95, 131.17, 128.19, 127.15, 126.43, 125.65, 122.10, 116.11, 47.40, 44.31, 42.64, 41.01, 37.51, 26.37, 21.08. $[\alpha]_{\mathrm{D}}^{20}=-53 \mathrm{deg} \cdot \mathrm{cm}^{3} \cdot \mathrm{dm}^{-1} \cdot \mathrm{g}^{-1}$ (c $7.900 \mathrm{~g} / \mathrm{L}, \mathrm{CH}_{2} \mathrm{Cl}_{2}$ ). HRMS (ESI) calcd. for $\mathrm{C}_{22} \mathrm{H}_{22} \mathrm{~N}_{2}{ }^{+}[\mathrm{M}+\mathrm{H}]^{+}$315.1783, found 315.1849.

\subsubsection{Synthesis of 6}

A mixture of Compound 5 ( $0.3 \mathrm{~g}, 1 \mathrm{mmol}, 1 \mathrm{eq})$, acetone $(6 \mathrm{~mL})$, acetic acid $(3 \mathrm{~mL})$, and water $(2 \mathrm{~mL})$ was stirred at $0{ }^{\circ} \mathrm{C} . \mathrm{KMnO}_{4}(0.8 \mathrm{~g}, 5 \mathrm{mmol}, 5 \mathrm{eq})$ was then slowly added over $3 \mathrm{~h} . \mathrm{H}_{2} \mathrm{O}_{2}(5$ $\mathrm{mL}, 30 \%$ ) was added dropwise at $0{ }^{\circ} \mathrm{C}$ giving rise to a strong foam. The mixture was then extracted with $\mathrm{CH}_{2} \mathrm{Cl}_{2}(3 \times 50 \mathrm{~mL})$, and the combined organic phases were washed with water $(3 \times 50 \mathrm{~mL})$. Solvents were evaporated, and the residue was purified using a gradient of eluent n-heptane:EtOAC (6:4) and then EtOAc $(100 \%)$. Compound $6(0.10 \mathrm{~g}, 29 \%$ yield, $\mathrm{Rf}=0.5)$ was obtained as a light yellow solid. ${ }^{1} \mathrm{H}-\mathrm{NMR}$ : $\left(300 \mathrm{MHz}, \mathrm{CDCl}_{3}\right) \delta=13.13(\mathrm{~s}, 1 \mathrm{H}, \mathrm{H} 21), 7.98(\mathrm{~d}, J=9.4 \mathrm{~Hz}, 1 \mathrm{H}, \mathrm{H} 3), 7.68(\mathrm{~s}, 1 \mathrm{H}$, H10), $7.54(\mathrm{dd}, J=21.8,8.6 \mathrm{~Hz}, 2 \mathrm{H}, \mathrm{H} 6, \mathrm{H7}), 6.86(\mathrm{~d}, J=9.3 \mathrm{~Hz}, 1 \mathrm{H}, \mathrm{H} 2), 4.12(\mathrm{q}, J=7.0 \mathrm{~Hz}, \mathrm{H} 15), 3.97$ (m, 1H, H16), 3.03 (t, J = 5.6 Hz, 1H, H13), $2.80(\mathrm{~m}, 1 \mathrm{H}, \mathrm{H} 14 \mathrm{a}), 2.64(\mathrm{~m}, 2 \mathrm{H}, \mathrm{H} 20), 1.48(\mathrm{~d}, J=9.1 \mathrm{~Hz}$, 1H, H14b), 1.46 (s, 3H, H19), 0.72 (s, 3H, H18). ${ }^{13} \mathrm{C}-\mathrm{NMR}\left(75 \mathrm{MHz}, \mathrm{CDCl}_{3}\right) \delta=178.09,164.39,160.49$, 143.11, 141.46, 135.73, 135.36, 130.73, 127.29, 124.50, 121.51, 121.47, 117.56, 47.65, 43.36, 42.77, 41.36, 38.02, 28.96, 26.34, 21.27. IR: (ATR, $\mathrm{cm}^{-1}$ ) $3161 \mathrm{w}(\mathrm{br}), 2927 \mathrm{~m}, 2542 \mathrm{w}(\mathrm{br}), 1614 \mathrm{~s}, 840 \mathrm{~s}(\mathrm{sh})[\alpha]_{\mathrm{D}}^{20}=+359$ deg. $\mathrm{cm}^{3} \cdot \mathrm{dm}^{-1} \cdot \mathrm{g}^{-1}$ (c $4.800 \mathrm{~g} / \mathrm{L}, \mathrm{CH}_{2} \mathrm{Cl}_{2}$ ). HRMS (ESI) calcd. for $\mathrm{C}_{21} \mathrm{H}_{20} \mathrm{~N}_{2} \mathrm{O}_{3}{ }^{+}[\mathrm{M}+\mathrm{H}]^{+} 349.1547$, found 349.1536. Crystal data: $\mathrm{C}_{21} \mathrm{H}_{20} \mathrm{~N}_{2} \mathrm{O}_{3}, M_{r}=348.39$, orthorhombic, $P 2_{1} 2_{1} 2_{1}$ (No. 19), a = 6.2818(8) $\AA, \mathrm{b}=14.5974(17) \AA, \mathrm{c}=19.054(3) \AA, a=b=g=90^{\circ}, V=1747.2(4) \AA^{3}, T=250(2) \mathrm{K}, \mathrm{Z}=4, Z^{\prime}=1$, $\mu\left(\mathrm{MoK}_{a}\right)=0.089,25,010$ reflections measured, 3517 unique $\left(R_{\text {int }}=0.2809\right)$, which were used in all calculations. The final $w R_{2}$ was 0.0936 (all data), and $R_{1}$ was $0.0462(\mathrm{I}>2(\mathrm{I})$ ).

\subsubsection{Quantum-Chemical Calculations}

Quantum-chemical calculations were performed by using the Gaussian 09 program suite [33]. The M06-2X functional $[34,35]$ was used with the TZVP basis set [36]. This fitted hybrid meta-GGA functional with $54 \% \mathrm{HF}$ exchange was especially developed to describe main group thermochemistry and the non-covalent interactions, showing very good results in the prediction of the position of the tautomeric equilibrium in azo naphthols possessing intramolecular H-bonds [37] and in the description of the proton transfer reactions in naphthols [38,39]. All structures were optimized without restrictions, using tight optimization criteria and an ultrafine grid in the computation of two electron integrals 
and their derivatives, and the true minima were verified by performing frequency calculations in the corresponding environment. Solvent effects were described by using the polarizable continuum model (the integral equation formalism variant, IEFPCM, as implemented in Gaussian 09) [40].

The optimized at the M06-2X/TZVP level structures of tautomers and/or dimers were used without further optimization for absorption spectra and NMR chemical shieldings' prediction in the same solvent by changing the basis set to B3LYP/6-311+G(2d,p). The absorption spectra of the compounds were predicted using the TD-DFT formalism [41-43]. The NMR chemical shieldings were calculated using the GIAO approximation [44] at the B3LYP/6-311+G(2d,p) level of theory. This level of theory was recommended in the pioneering work by Cheeseman et al. [45] focused on the comparison of different models for calculating nuclear magnetic resonance shielding tensors and showed very good results in predicting the NMR spectra of azo-hydrazone tautomerism [46]. The calculated absolute shieldings were transformed to chemical shifts using the reference compound tetramethylsilane, $\mathrm{Si}\left(\mathrm{CH}_{3}\right)_{4}$, for hydrogen: $\delta=\delta_{\text {calc }}($ ref $)-\delta_{\text {calc }}$. Both $\delta_{\text {calc }}($ ref $)$ and $\delta_{\text {calc }}$ were evaluated at the same computational level.

In the case of dimers, counterpoise corrections were computed in the gas phase using the methodology integrated [47] in the Gaussian 09 program suite.

\section{Conclusions}

In conclusion, the tautomerism and self-association of two novel ligands derived from pinene were characterized spectroscopically and corroborated with the theoretical calculations obtained by DFT. The keto-enol tautomerism of Compound 3 was studied by means of DFT calculations, ${ }^{1} \mathrm{H}-\mathrm{NMR}$, and UV-Vis spectroscopy. The existence of two distinct sets of signals for each of the tautomers allowed a quantitative estimation of the tautomeric ratio, giving access to the $\mathrm{K}_{\mathrm{T}}=$ [enol]/[keto], $\Delta \mathrm{G}^{\circ}, \Delta \mathrm{H}^{\circ}$, and $\Delta \mathrm{S}^{\circ}$ values. Depending on the solvent, the $\Delta \mathrm{G}^{\circ}$ values were in the range of -0.46 to $0.28 \mathrm{kcal} / \mathrm{mol}$, in good agreement with the calculated values.

Although Compound $\mathbf{6}$ was potentially tautomeric, it existed as a single lactam tautomer due to the high energy difference between the two potential tautomers. The compound aggregated through $\mathrm{H}$-bonding between the lactam moiety and the carboxylic acid, as shown by ${ }^{1} \mathrm{H}-\mathrm{NMR}$, single crystal X-ray diffraction and DFT calculations.

Supplementary Materials: The following are available online: Figure S1: Influence of the water content on the keto-enol equilibrium $3 \mathbf{k} \rightleftharpoons 3 \mathbf{e}\left(62 \mathrm{mM}\right.$ in $\left.\mathrm{CD}_{3} \mathrm{CN}\right)$; Figure S2. Dependence of the free enthalpy $\left(\Delta \mathrm{G}^{\circ}\right)$ as a function of temperature for Compound $3\left(\left(62 \mathrm{mM}\right.\right.$ in $\left.\mathrm{CD}_{3} \mathrm{CN}\right)$, from VT ${ }^{1} \mathrm{H}-\mathrm{NMR}$ experiments; Figure S3. Absorption spectra of 3 in organic solvents; Figure S4. Absorption spectra of 6 in $\mathrm{CH}_{3} \mathrm{CN}$ while keeping the product of the concentration value and the path length constant; Figures S5-S19: NMR spectra; Figures S19-S26: MS spectra; Table S1. The most stable isomers of the existing tautomers of 6 in chloroform; Table S2. Predicted absorption spectra of the monomer and dimer of $\mathbf{6}$ in DMSO; Table S2. Predicted absorption spectra of the monomer and dimer of $\mathbf{6}$ in DMSO; Table S3. Crystallographic data for $\mathbf{6}$.

Author Contributions: Conceptualization, A.B.S. and O.M.; Data curation, A.B.S., A.C. and C.A.; Formal analysis, A.B.S. and L.A.; Investigation, A.B.S. and I.C.; Methodology, V.D., L.A. and C.A.; Project administration, O.M.; Supervision, O.M.; Writing—original draft, A.B.S.; Writing-review \& editing, I.C., K.M.F., L.A., C.A. and O.M. All authors have read and agreed to the published version of the manuscript.

Funding: This research was funded by the Haute Ecole d'Ingénierie et d'Architecture Fribourg (ChemTech Institute) and the University of Fribourg.

Acknowledgments: The authors thank Albert Ruggi for measuring the HRMS spectra.

Conflicts of Interest: The authors declare no conflict of interest.

\section{References}

1. Lama, M.; Mamula, O.; Kottas, G.S.; De Cola, L.; Stoeckli-Evans, H.; Shova, S. Enantiopure, Supramolecular Helices Containing Three-Dimensional Tetranuclear Lanthanide (III) Arrays: Synthesis, Structure, Properties, and Solvent-Driven Trinuclear/Tetranuclear Interconversion. Inorg. Chem. 2008, 47, 8000-8015. [CrossRef] [PubMed] 
2. Von Zelewsky, A.; Mamula, O. The bright future of stereoselective synthesis of co-ordination compounds. J. Chem. Soc. Dalton Trans. 2000, 219-231. [CrossRef]

3. Mamula, O.; Von Zelewsky, A.; Bark, T.; Bernardinelli, G. Stereoselective Synthesis of Coordination Compounds: Self-Assembly of a Polymeric Double Helix with Controlled Chirality. Angew. Chem. Int. Ed. 1999, 38, 2945-2948. [CrossRef]

4. Perret-Aebi, L.-E.; von Zelewsky, A.; Neels, A. Diastereoselective preparation of $\mathrm{Cu}(\mathrm{I})$ and $\mathrm{Ag}(\mathrm{I})$ double helices by the use of chiral bis-bipyridine ligands. New J. Chem. 2009, 33, 462-465. [CrossRef]

5. Mamula, O.; Bark, T.; Quinodoz, B.; Stoeckli-Evans, H.; von Zelewsky, A. Self-assembly of Ag(I) helicates with new enantiopure 5,6-Chiragen type ligands. Inorg. Chim. Acta 2018, 475, 200-206. [CrossRef]

6. Rich, J.; Rodríguez, M.; Romero, I.; Vaquer, L.; Sala, X.; Llobet, A.; Corbella, M.; Collomb, M.-N.; Fontrodona, X. $\mathrm{Mn}(\mathrm{ii})$ complexes containing the polypyridylic chiral ligand (-)-pinene [5,6]bipyridine. Catalysts for oxidation reactions. Dalton Trans. 2009, 38, 8117-8126. [CrossRef]

7. Chelucci, G.; Saba, A. New 1,10-phenanthroline ligands for asymmetric catalysis: Enantioselective palladium catalyzed allylic substitution. Tetrahedron Asymmetry 1998, 9, 2575-2578. [CrossRef]

8. Schmitz, C.; Leitner, W.; Franciò, G. Pinene-derived monodentate phosphoramidites for asymmetric hydrogenation. Eur. J. Org. Chem. 2015, 2015, 2889-2901. [CrossRef]

9. Solea, A.B.; Wohlhauser, T.; Abbasi, P.; Mongbanziama, Y.; Crochet, A.; Fromm, K.M.; Novitchi, G.; Train, C.; Pilkington, M.; Mamula, O. Versatile synthesis of chiral 6-oxoverdazyl radical ligands-new building blocks for multifunctional molecule-based magnets. Dalton Trans. 2018, 47, 4785-4789. [CrossRef]

10. Hayoz, P.; Von Zelewsky, A. New versatile optically active bipyridines as building blocks for helicating and caging ligands. Tetrahedron Lett. 1992, 33, 5165-5168. [CrossRef]

11. Lama, M.; Mamula, O.; Scopelliti, R. Enantiopure Oxygen-Functionalized Bipyridine Derivatives: Synthesis and Characterization. Synlett 2004, 10, 1808-1810.

12. Malkov, A.V.; Baxendale, I.R.; Bella, M.; Langer, V.; Fawcett, J.; Russell, D.R.; Mansfield, D.J.; Valko, M.; Kočovský, P. Synthesis of New Chiral 2,2'-Bipyridyl-Type Ligands, Their Coordination to Molybdenum(0), Copper(II), and Palladium(II), and Application in Asymmetric Allylic Substitution, Allylic Oxidation, and Cyclopropanation. Organometallics 2001, 20, 673-690. [CrossRef]

13. Chelucci, G.; Saba, A.; Sanna, G.; Soccolini, F. Chiral 2,2'-bipyridines, 5,6-dihydro-1,10-phenanthrolines and 1,10-phenanthrolines as ligands for enantioselective palladium catalyzed allylic substitution. Tetrahedron Asymmetry 2000, 11, 3427-3438. [CrossRef]

14. Kumbhar, S.V.; Chen, C. Enantioselective Nozaki-Hiyama-Kishi allylation-lactonization for the syntheses of 3-substituted phthalides. Rsc Adv. 2018, 8, 41355-41357. [CrossRef]

15. Hayoz, P.; von Zelewsky, A.; Stoeckli-Evans, H. Stereoselective Synthesis of Octahedral Complexes with Predetermined Helical Chirality. J. Am. Chem. Soc. 1993, 115, 5111-5114. [CrossRef]

16. Mürner, H.; Von Zelewsky, A.; Stoeckli-Evans, H. Octahedral complexes with predetermined helical chirality: Xylene-bridged bis([4,5]-pineno-2,2'-bipyridine) ligands (chiragen[o-, m-, p-xyl]) with ruthenium(II). Inorg. Chem. 1996, 35, 3931-3935. [CrossRef]

17. Murner, H.; von Zelewsky, A.; Hopfgartner, G. Dinuclear metal complexes of Cd(II), Zn(II) and Fe(II) with triple-helical structure and predetermined chirality. Inorg. Chim. Acta 1998, 271, 36-39. [CrossRef]

18. Mamula, O.; Monlien, F.J.; Porquet, A.; Hopfgartner, G.; Merbach, A.E.; Von Zelewsky, A. Self-assembly of multinuclear coordination species with chiral bipyridine ligands: Silver complexes of 5,6-CHIRAGEN (o,m,p-xylidene) ligands and equilibrium behaviour in solution. Chem. Eur. J. 2001, 7, 533-539. [CrossRef]

19. Mürner, H.; Belser, P.; Von Zelewsky, A. New configurationally stable chiral building blocks for polynuclear coordination compounds: $\mathrm{Ru}$ (chiragen[X])Cl 2 . J. Am. Chem. Soc. 1996, 118, 7989-7994. [CrossRef]

20. Gladiali, S.; Chelucci, G.; Mudadu, M.S.; Gastaut, M.A.; Thummel, R.P. Friedländer synthesis of chiral alkyl-substituted 1,10-phenanthrolines. J. Org. Chem. 2001, 66, 400-405. [CrossRef]

21. Chelucci, G.; Loriga, G.; Murineddu, G.; Pinna, G.A. Synthesis of chiral C2-symmetric 1,10-phenanthrolines from naturally occurring monoterpenes. Synthesis 2003, 73-78. [CrossRef]

22. Gawinecki, R.; Kolehmainen, E.; Loghmani-Khouzani, H.; Ośmiałowski, B.; Lovász, T.; Rosa, P. Effect of $\pi$-electron delocalization on tautomeric equilibria - Benzoannulated 2-phenacylpyridines. Eur. J. Org. Chem. 2006, 2817-2824. [CrossRef]

23. Antonov, L.; Fabian, W.M.F.; Taylor, P.J. Tautomerism in some aromatic Schiff bases and related azo compounds: An LSER study. J. Phys. Org. Chem. 2005, 18, 1169-1175. [CrossRef] 
24. Skotnicka, A.; Czeleń, P.; Gawinecki, R. Tautomeric Equilibria in Solutions of 2-Phenacylbenzimidazoles. Heteroat. Chem. 2019. [CrossRef]

25. Pol, P.D.; Mahesh, R.T.; Nandibewoor, S.T. Kinetics and mechanism of chromium(III) catalyzed oxidation of 1,10-phenanthroline by alkaline permanganate. React. Kinet. Catal. Lett. 2004, 81, 113-119. [CrossRef]

26. Mason, S.F. The tautomerism of N-heteroaromatic hydroxy-compounds. Part I. Infrared spectra. J. Chem. Soc. 1957, 980, 4874-4880. [CrossRef]

27. Dey, A.S.; Joullié, M.M. Synthesis and properties of fluorine-containing heterocyclic compounds. II. trifluoromethyl benzo[h]quinolines, benzo[h]-1,6-napthyridines, 1,7- and 1,10-phenanthrolines. J. Heterocycl. Chem. 1965, 2, 120-125. [CrossRef]

28. Goldsmith, M.R.; Jayasuriya, N.; Beratan, D.N.; Wipf, P. Optical Rotation of Noncovalent Aggregates. J. Am. Chem. Soc. 2003, 125, 15696-15697. [CrossRef]

29. Steiner, T. The hydrogen bond in the solid state. Angew. Chem. Int. Ed. 2002, 41, 49-76. [CrossRef]

30. Sheldrick, G.M. SHELXT-Integrated space-group and crystal-structure determination. Acta Cryst. Sect. A Found. Cryst. 2015, 71, 3-8. [CrossRef]

31. Dolomanov, O.V.; Bourhis, L.J.; Gildea, R.J.; Howard, J.A.K.; Puschmann, H. OLEX2: A complete structure solution, refinement and analysis program. J. Appl. Cryst. 2009, 42, 339-341. [CrossRef]

32. Sheldrick, G.M. Crystal structure refinement with SHELXL. Acta Cryst. Sect. C Struct. Chem. 2015, 71, 3-8. [CrossRef]

33. Bulik, I.W.; Scalmani, G.; Frisch, M.J.; Scuseria, G.E. Noncollinear density functional theory having proper invariance and local torque properties. Phys. Rev. B 2013, 87, 035117. [CrossRef]

34. Zhao, Y.; Truhlar, D.G. Density Functionals with Broad Applicability in Chemistry. Acc. Chem. Res. 2008, 41, 157-167. [CrossRef] [PubMed]

35. Zhao, Y.; Truhlar, D.G. The M06 suite of density functionals for main group thermochemistry, thermochemical kinetics, noncovalent interactions, excited states, and transition elements: Two new functionals and systematic testing of four M06-class functionals and 12 other function. Chem. Acc. 2007, 120, 215-241. [CrossRef]

36. Weigend, F.; Ahlrichs, R. Balanced basis sets of split valence, triple zeta valence and quadruple zeta valence quality for H to Rn: Design and assessment of accuracy. Phys. Chem. Chem. Phys. 2005, 7, 3297. [CrossRef]

37. Kawauchi, S.; Antonov, L. Description of the Tautomerism in Some Azonaphthols. J. Phys. Org. Chem. 2013, 26, 643-652. [CrossRef]

38. Manolova, Y.; Kurteva, V.; Antonov, L.; Marciniak, H.; Lochbrunner, S.; Crochet, A.; Fromm, K.M.; Kamounah, F.S.; Hansen, P.E. 4-Hydroxy-1-naphthaldehydes: Proton transfer or deprotonation. Phys. Chem. Chem. Phys. 2015, 17, 10238-10249. [CrossRef]

39. Manolova, Y.; Marciniak, H.; Tschierlei, S.; Fennel, F.; Kamounah, F.S.; Lochbrunner, S.; Antonov, L. Solvent control of intramolecular proton transfer: Is 4-hydroxy-3-(piperidin-1-ylmethyl)-1-naphthaldehyde a proton crane? Phys. Chem. Chem. Phys. 2017, 19, 7316-7325. [CrossRef]

40. Tomasi, J.; Mennucci, B.; Cammi, R. Quantum Mechanical Continuum Solvation Models. Chem. Rev. 2005, 105, 2999-3094. [CrossRef]

41. Improta, R. UV-Visible Absorption and Emission Energies in Condensed Phase by PCM/TD-DFT Methods. Comput. Strat. Spectrosc. 2011, 37-75.

42. Kawauchi, S.; Antonov, L.; Okuno, Y. Prediction of the color of dyes by using time-dependent density functional theory (TD-DFT). Bulg. Chem. Commun. 2014, 46, 228-237.

43. Jacquemin, D.; Mennucci, B.; Adamo, C. Excited-state calculations with TD-DFT: From benchmarks to simulations in complex environments. Phys. Chem. Chem. Phys. 2011, 13, 16987. [CrossRef] [PubMed]

44. Wolinski, K.; Hinton, J.F.; Pulay, P. Efficient implementation of the gauge-independent atomic orbital method for NMR chemical shift calculations. J. Am. Chem. Soc. 1990, 112, 8251-8260. [CrossRef]

45. Cheeseman, J.R.; Trucks, G.W.; Keith, T.A.; Frisch, M.J. A comparison of models for calculating nuclear magnetic resonance shielding tensors. J. Chem. Phys. 1996, 104, 5497-5509. [CrossRef]

46. Deneva, V.; Lyčka, A.; Hristova, S.; Crochet, A.; Fromm, K.M.; Antonov, L. Tautomerism in azo dyes: Border cases of azo and hydrazo tautomers as possible NMR reference compounds. Dye. Pigm. 2019, 165, 157-163. [CrossRef]

47. Simon, S.; Duran, M.; Dannenberg, J.J. How does basis set superposition error change the potential surfaces for hydrogen-bonded dimers? J. Chem. Phys. 1996, 105, 11024-11031. [CrossRef] 
Sample Availability: Samples of the compounds 1-6 are available from the authors.

(C) 2020 by the authors. Licensee MDPI, Basel, Switzerland. This article is an open access article distributed under the terms and conditions of the Creative Commons Attribution (CC BY) license (http://creativecommons.org/licenses/by/4.0/). 